\title{
As vivências da amamentação para um grupo de mulheres: nos limites de ser "o corpo para o filho" e de ser "o corpo para si"
}

\author{
Breastfeeding experiences in a group of women: \\ the limits of "the body for the child" \\ and "the body for oneself"
}

Ana Márcia Spanó Nakano ${ }^{1}$

\footnotetext{
${ }^{1}$ Departamento de Enfermagem MaternoInfantil e Saúde Pública, Escola de Enfermagem de Ribeirão Preto, Universidade de São Paulo. Av. Bandeirantes 3900 , Ribeirão Preto, SP 14040-902, Brasil. nakano@eerp.usp.br
}

\begin{abstract}
This study aims to understand the meanings ascribed by a group of women from Ribeirão Preto, São Paulo State, to their experiences with breastfeeding in relation to the sensations and manifestations in their own bodies as well as those they perceive in their children. The phenomenon was viewed as integrated with value systems related to motherhood and the body. The research methodology was qualitative. Participants included twenty primiparous women who had given birth less than 30 days previously who came to primary health care clinics due to various complaints. The analysis of interviews and observations was based on the thematic modality of content analysis. For these women, breastfeeding means to be a good mother and to give the best of oneself to the child. In breastfeeding practice, among limits and possibilities, they measure what they consider a "problem" based on the perceived manifestations in their own bodies and especially in those of their children. Their concerns are based on harm and danger to which they expose the child. Such experiences play out at the limits of being: the body for the child and the body for oneself, thereby establishing a sharp conflict between motherhood and individuality.
\end{abstract}

Key words Breastfeeding; Women's Health; Mothers

Resumo Neste estudo buscamos compreender o significado atribuído, por um grupo de mulheres da cidade de Ribeirão Preto, São Paulo, sobre as vivências da amamentação no que se refere às sensações e manifestações em seus corpos, bem como as percebidas nos corpos de seus filhos. Compreendemos esse fenômeno integrado a sistemas de valores da maternidade e do corpo. Constitui-se de uma pesquisa qualitativa. Participaram vinte primíparas com parto há menos de trinta dias, que procuraram as unidades básicas de saúde por razão adversa à amamentação. A análise das entrevistas e observações baseou-se na técnica de análise de conteúdo, modalidade temática. Para essas mulheres, amamentar é ser uma boa mãe e dar o melhor para o filho. Na prática da amamentação, entre limites e possibilidades, dimensionam o que consideram "problema", baseando-se nas manifestações percebidas em seus corpos e, prioritariamente, nos corpos de seus filhos. Suas preocupações estão fundadas nos prejuízos e perigos a que expõem o filho. Tais vivências se processam nos limites de ser: o corpo para o filho e o corpo para si, o que confere um vivido conflito entre maternidade e individualidade.

Palavras-chave Aleitamento Materno; Saúde da Mulher; Mães 
O conhecimento científico sobre amamentação comprova as propriedades ímpares do leite humano e traz esclarecimentos sobre o processo da lactação. Entretanto, a amamentação não se esgota apenas em fatos biológicos, mas abrange dimensões construídas cultural, social e historicamente. Lacunas na construção desse saber podem ser observadas na medida em que somente nas últimas décadas a amamentação passa a ser vista também como uma prática social e culturalmente construída.

Trabalhos na área de história social analisam a construção de significados da amamentação e maternidade através dos tempos, entre eles o de Ariès (1981), Donzelot (1980), Costa (1983), Badinter (1985) e Silva (1990). Evidenciam que o comportamento feminino frente ao aleitamento materno guarda uma relação com o lugar, a imagem social da mulher e a maternidade, e ele se apresenta variável nas diferentes épocas e contextos sociais, dependente de valores e interesses econômicos e políticos. Além desses trabalhos, estudos etnográficos demonstram a diversidade de significados que a amamentação e a própria maternidade adquirem em diferentes culturas, como o de Mead (1979). A literatura científica nacional, embora escassa, apresenta estudos (Bitar, 1995; Maués, 1998; Van Der Sand, 1999; Victora, 1996), realizados em diferentes regiões do país, evidenciando aspectos da cultura no delineamento da prática da amamentação.

Na década de 90, utilizando-se de referenciais teóricos da fenomenologia, do interacionismo simbólico, das representações sociais e das relações sociais de gênero, autores como Arantes (1991), Souza (1993), Silva (1997), Araújo (1991) e Nakano (1996), trazem construções que evidenciam o aleitamento materno como um processo centrado na mulher, tendo seus significados elaborados com base na experiência social, no cotidiano das famílias e vivido pelas mulheres em consonância ou em conflito.

Na construção de um novo paradigma para o aleitamento materno, Almeida (1999) considera a necessidade de transcender o biológico em direção ao social, não para estabelecer causa e efeito, mas para possibilitar a percepção da amamentação como categoria híbrida, que se forma entre os domínios da natureza e da cultura. Embora se reconheça a amamentação como fenômeno multidimensional, nas ações assistenciais às mulheres, tal abordagem tem se apresentado bastante fragilizada.

A esse respeito, Adesse (1994), investigando sobre os pontos críticos para o impedimento da prática do aleitamento materno entre mulheres de baixa renda no Rio de Janeiro, adverte para a necessidade de se entender melhor as queixas de ordem biológica, por serem apenas "racionalizações" de certos impedimentos que freqüentemente são enfrentados pelas mulheres, sem apoio e sem diálogo.

Vale considerar o contexto de nossos serviços de saúde, onde predomina o modelo de pronto-atendimento e as ações são desencadeadas, tendo por base a queixa de ordem biológica apresentada, que se fecha para qualquer possibilidade de espaço de interação com as mulheres, impossibilitando o profissional de apreender o que há por trás dos sinais e sintomas. Se de um lado temos o profissional de saúde que se volta ao corpo como mero depositário de processos biológicos indicadores de saúde e doença, por outro, temos as mulheres que tendem a interpretar as sensações corporais de acordo com códigos específicos de seu meio, nem sempre congruentes com os dos profissionais de saúde.

Aproveitando o momento em que realizávamos, no Município de Ribeirão Preto, em 1999, uma pesquisa epidemiológica sobre alimentação de crianças no primeiro ano de vida, como parte do Projeto Amamentação e Municípios, do Instituto de Saúde da Secretaria de Saúde do Estado de São Paulo (SES-SP) e do Núcleo de Pesquisas Epidemiológicas em Nutrição e Saúde (NUPENS) da Faculdade de Saúde Pública (FSP) da Universidade de São Paulo (USP), buscamos investigar as situações consideradas pelas mulheres como "problema na amamentação" e qual a demanda pelos serviços de saúde local. Do total de 1.499 mulheres entrevistadas, 646 (43\%) referiram ter apresentado "problemas na amamentação". Dentre os problemas identificados incluíam: 472 (73\%) com as mamas, $60(10,2 \%)$ com as mamas e o bebê, 58 $(8,4 \%)$ com o bebê, 29 (4,5\%) outros motivos e $23(3,2 \%)$ não registrados. Apesar do equipamento assistencial (unidades básicas de saúde, hospitais e banco de leite humano) de que a cidade dispõe para atender às questões de amamentação, apenas $358(55,4 \%)$ das mulheres que referiram "problemas" procuraram assistência nos serviços de saúde local. É possível supor que, por trás dessa baixa demanda pelos serviços de saúde, existam questões culturais, sociais e subjetivas que envolvam a forma como essas mulheres percebem e agem frente à prática da amamentação, bem como aspectos relacionados à estrutura dos serviços de saúde.

Frente a essa realidade, desenvolvemos este trabalho buscando aclarar aspectos relacionados ao significado atribuído pelas mulheres às sensações e manifestações em seus corpos, bem como as percebidas nos corpos de seus fi- 
lhos, como alteração ou normalidade no processo da amamentação. Questionamos o que constitui "problemas na amamentação" para as mulheres.

Buscamos analisar as representações sobre amamentação como parte do universo simbólico das mulheres que integra sistemas de valores mais amplos da maternidade e do corpo. Em nossa sociedade, a maternidade é socialmente valorizada e instituída como responsabilidade/dever da mulher pelo cuidado com o filho, o que está em parte fundamentada na capacidade que ela tem de engravidar, parir e amamentar e em construções sociais de serem as mulheres mais ternas, carinhosas e habilidosas para cuidar da prole. Nesse sentido, é possível supor que o valor atribuído à priorização do filho recém-nascido estaria por vezes ofuscando a atenção das mulheres frente às manifestações em seus corpos, considerando "problema na amamentação” aquele que resulta em prejuízo para a criança.

A apropriação social do corpo feminino para o exercício da maternidade, especificamente da amamentação, é estrategicamente importante de ser analisado como categoria própria, por ser o corpo, conforme refere Rodrigues (1986), algo natural e individual, sendo conformado e moldado socialmente.

As sensações corporais e as práticas que se passam no corpo materno são determinadas por representações culturais de maternidade e imprimem maneiras socialmente reconhecidas de perceber e agir frente a situações que se apresentam na amamentação, podendo ser vivenciadas pelas mulheres em consonância ou em conflito com as determinações sociais, deixando emergir seus limites.

\section{Metodologia}

Este trabalho constitui-se em uma pesquisa qualitativa. O universo empírico considerado foi de puérperas freqüentadoras das Unidades Básicas de Saúde (UBS) da Secretaria de Saúde do Município de Ribeirão Preto. Como critério de seleção do campo de investigação, optamos pelas unidades de saúde que obtiveram, segundo os resultados da pesquisa epidemiológica sobre alimentação de crianças no primeiro ano de vida, no Município de Ribeirão Preto, o maior e o menor valor referente ao indicador Aleitamento Materno Exclusivo (AME), considerando possíveis diversidades da prática da amamentação entre as mulheres dessas unidades de saúde.

O recorte empírico do estudo foi constituído por vinte mulheres primíparas que procura- ram a UBS por razão adversa a questões da amamentação, incluindo as que estavam ou não amamentando, distribuídas eqüitativamente entre as UBSs de maior e menor valor no indicador AME. A escolha das primíparas permitiu uma maior homogeneização entre os sujeitos do estudo. Não fizeram parte da amostra mulheres que tiveram filhos prematuros, com malformação ou qualquer intercorrência que dificulte ou requeira cuidados específicos com amamentação. Ainda como critério, incluímos as mulheres que estavam no período pós-parto inferior a um mês, por ser esse um período reconhecido como de maior incidência de intercorrências no processo de lactação.

Apesar de partirmos das unidades básicas de saúde na identificação dos sujeitos estudados, as entrevistas foram realizadas no domicílio. As entrevistas, do tipo semi-estruturadas, duraram em torno de uma hora e meia, sendo abordados os seguintes conteúdos: dados de identificação; o processo reprodutivo, particularmente sobre amamentação (descrição de experiências, procedimentos, hábitos e rotinas, conhecimentos, percepções e valores frente às dificuldades) e informações sobre a unidade familiar/contexto relacional. Todas as entrevistas foram gravadas, após consentimento informado e esclarecido das depoentes. O corpus de análise foi composto pelos dados das entrevistas e observações descritas nos diários de campo, os quais foram analisados por meio do método de análise de conteúdo, modalidade temática (Bardin, 1977). As discussões das categorias temáticas depreendidas estão fundamentadas nas concepções de corpo e maternidade.

A pesquisa teve aprovação do Comitê de Ética da Escola de Enfermagem de Ribeirão Preto da USP. Atendendo aos princípios éticos, utilizamos nomes fantasia para nos referirmos às depoentes na apresentação dos resultados.

\section{Resultados}

As entrevistadas são mulheres de baixa renda, moradoras em bairros da periferia da cidade de Ribeirão Preto. A maioria (13) do grupo de mulheres é constituída por jovens adolescentes com idade variando de 15 a 19 anos, sendo que as sete restantes estão em idade adulta que variou de 20 a 26 anos. A conclusão dos estudos de Ensino Médio é condição observável em apenas seis do total de mulheres do estudo; dez interromperam os estudos sendo que, dessas, seis no primeiro grau (5 com primeiro grau incompleto e 1 completo) e quatro no segundo grau. No momento da pesquisa, quatro estavam es- 
tudando no segundo grau, em regime de licença concedida pela escola. O grupo é composto por cinco mulheres casadas, oito em união consensual e sete solteiras.

A maioria das mulheres (14) iniciou no mercado de trabalho em idade precoce, dos 11 aos 16 anos. Na atualidade, apenas duas estão engajadas no mercado formal, as demais estão desempregadas com planos futuros de retorno, na dependência das imposições da maternidade e do suporte que terá do seu meio relacional. O trabalho é pensado tendo por referência a maternidade como prioridade, devendo adequar-se a esta.

Para a compreensão dos significados das vivências das mulheres na amamentação, tomamos por referência o universo cultural específico de um dado grupo social, mulheres de classes populares, o qual pode contudo diferir, conforme a condição particular (idade, escolaridade, entre outras) do agente social, e essas diferenças não foram consideradas na análise.

\section{Os significados das vivências relacionadas à amamentação para essas mulheres}

A amamentação, como forma de expressão da relação estabelecida entre o corpo do lactente (filho) e o corpo da mulher (mãe), perpassa o poder de imposição do universo simbólico que dá sentido à prática da amamentação para essas mulheres, ao mesmo tempo que faz emergir dissimulações, que depreendemos como limites do corpo materno: "ser o corpo para o filho" e "ser o corpo para si”.

Aspectos da construção histórico-social do ser mulher, numa relação unívoca ao materno, evidenciam-se na prática da amamentação das mulheres estudadas, no sentido que atribuem ao corpo materno de "ser para o filho", apresentados nas unidades temáticas que passamos a descrever.

\section{Amamentar: ser uma boa mãe}

A maternidade, concebida no século XIX como sacerdócio, uma experiência feliz, mas que traz dores, sofrimento e sacrifícios (Badinter, 1985), dá significado à amamentação para essas mulheres. Amamentar é condição emblemática de ser uma boa mãe, como podemos depreender das falas.

"Senti que o bebê depende muito da mãe... mesmo saindo da barriga (...) estou fazendo esse sacrifício (...) é gostoso, mas faço com orgulho, mas chorando de dor (...) o difícil é o aleitamento, o resto a gente suporta" (Aline).
Para Citeli (1998:65), a mulher tem " $a m a$ ternidade como seu destino, seu lugar e função na sociedade e a reprodução parece estar circunscrita em um limbo, marcado pela naturalização".

Os atributos maternos aderem-se aos corpos (e mentes) das mulheres como se fossem parte de sua "natureza", o que podemos observar nos relatos sobre suas vivências na amamentação em que a dedicação e a sujeição justificam-se ante os resultados de ter o filho bem cuidado.

\section{Amamentação: dar o melhor para o bebê}

$\mathrm{O}$ ato de amamentar o filho mostra-se como importante mecanismo, perante a sociedade, para reafirmar o dever e a responsabilidade da mãe. No mundo simbólico das mulheres pesquisadas, o desejo e o dever de amamentar emergem do mesmo universo moral, o de considerar como dimensão precípua os atributos que atrelam o feminino ao materno.

As mulheres constroem o valor da prática da amamentação como o melhor para o bebê, tendo por base a experiência social, apropriando-se do discurso médico, e reinterpretando-o, como depreendemos do depoimento abaixo.

"O leite materno é o melhor alimento para a criança para ela desenvolver, o leite materno tem tudo, tem água, tem vitamina, tem o açúcar, é a temperatura normal pra a criança e não precisa fazer mamadeira. Previne várias doenças, uma alergia, a gente também é prevenida com o câncer que dá na mama, e outras coisas, então o leite materno é muito importante para o crescimento" (Lucila).

As mulheres consideram importante amamentar por proporcionar uma boa condição de saúde e desenvolvimento para a criança. Por outro lado, menor relevância é atribuída pelas mulheres do estudo à amamentação como benefício à sua saúde, poupando-as de muitos cuidados com a alimentação da criança, bem como favorecendo o restabelecimento pós-parto e a prevenção do câncer. Dessa forma, a amamentação é pensada essencialmente como alimento, afeto e proteção necessários à saúde do bebê.

No universo de significados dessas mulheres, amamentar é ser uma boa mãe, é dar o melhor para o bebê, sendo estes os constituintes do princípio articulador que regem os significados que atribuem à prática da amamentação. 
Praticando amamentação:

saber quando ele (bebê) está com fome... quando está satisfeito

$\mathrm{O}$ atendimento das necessidades da criança tem suscitado, nas mulheres estudadas, um estado de prontidão e vigilância constantes no reconhecimento de sinais de bem-estar do filho em resposta à amamentação, como podemos depreender na fala abaixo.

"Sempre que ela acorda, pede o peito, abre o bocão procurando o peito (...) Eu tiro o peito ela continua procurando ... acho que não está satisfeita (...) ela está com um pouco de sono... ela fica mole e não mama mais, fica só chupetando ... eu tiro, coloco ela para arrotar(...)” (Marilda).

Considera Almeida (1999:78), "que a saciedade do bebê é uma preocupação que compõe o grupo de inquietações maternas nos primeiros dias após o parto, e pode estender-se por períodos maiores, a depender de fatores individuais $e$ coletivos que concorrem para a definição do regime alimentar praticado pelo lactente". O que usualmente se considera determinante nesse processo é a autoconfiança materna na capacidade de amamentar o próprio filho, apesar de importante, em verdade constitui apenas um dos fatores individuais, entre vários outros que são estabelecidos socioculturalmente.

Na pesquisa de Victora \& Knauth (2000), sobre hábitos alimentares em crianças menores de dois anos, para as mulheres da Região Sudeste, observam as autoras que o controle de horário para oferecimento do peito não aparece como importante na faixa de zero a cinco meses de idade, e sim nas manifestações da criança.

$\mathrm{Na}$ prática da amamentação, as mulheres orientam-se não só pelas manifestações da criança (sinais de procura: o choro, o chupar as mãos, a procura do peito), mas também pela natureza do processo reprodutivo que imprime e marca seus corpos (sinais de "prontidão" dos peitos: vaza, incha, fica duro): “...meu peito dói, não é que dói diz que enche (...) às vezes va$z a$, eu vejo que é hora de mamar (...) às vezes ele chora também, aí eu vejo que ele está com fome (...)" (Janete).

A busca por referências nas manifestações em seus corpos e nos corpos da criança, por essas mulheres, pode estar relacionada à adoção de uma prática de amamentação liberada de regras e normas construídas pelo processo de medicalização, que estabelece a regulamentação do horário das mamadas apresentado nos manuais de puericultura, originalmente do século XIX, advogados pelas escolas européias, em especial a francesa e a alemã. Refere Almeida (1999), que tais regras foram proscritas des- de a década de 80 , recomendando o regime de livre demanda, ou seja, a mãe ofereça a mama a seu filho quantas vezes ela for solicitada.

Praticando amamentação:

o bebê não queria pegar o peito

A cultura institucional da amamentação, fundamentada no reducionismo biológico, típico do modelo oitocentista, concebe à amamentação um atributo natural, comum a todas as espécies de mamíferos. Ao integrar a cultura popular, resulta em expectativas, por parte das mulheres, de que "amamentar é só oferecer o peito, o leite sai e o bebê mama”.

"Sugou na primeira (...) já chegou no mundo com fome (...) veio gritando" (Isabel).

A "naturalização" da resposta da criança ante o seio materno é cientificamente construída na psicologia, que considera a boca de um bebê como o centro de seu universo, a via pela qual se aplacam a fome e a sede, diminui a tensão e se restabelece o conforto. Dentro da lógica dessas mulheres, amamentar para atender às necessidades da criança, são essencialmente valorizadas e quando tais respostas não atendem às suas expectativas, ansiedades, conflitos e tensões são vividos por elas.

"Foi uma grande decepção...Eu colocava o peito na boca dele, dava ânsia" (Marisa).

"Eu não sabia (...) como era dar de mamar...ela pegava só o bico, por isso eu não tinha paciência porque ela machucava, doía, porque ela tinha que pegar tudo isso aqui (...) eu não estava conseguindo (...) era o meu jeito que não estava certo" (Suzana).

As mulheres tomam para si a culpa pelo seu "mal jeito" para amamentar, o que lhes parece resultar em um "não querer da criança" e o fato dela "não conseguir pegar".

Não ter “jeito” significa ser destituída de certas capacidades como conhecimento e prática, reforçando a idéia do aleitamento como prática aprendida e não instintiva. Usando das palavras de Badinter (1985:346), sobre as respostas consideradas instintivas, "as situações que se apresentam para as mulheres são demasiadamente numerosas para serem classificadas como exceções patológicas que confirmariam a regra". A mesma autora, referindo-se ao comportamento materno, considera que este não se apresenta suficientemente unificado para que se possa falar de instinto ou atitude materna em si. 
Praticando amamentação:

o leite não queria sair

A não-observação da saída concreta de leite e a manifestação de insatisfação da criança (choro constante), colocam em xeque a capacidade das mulheres em suprir adequadamente a necessidade da criança.

“Não saía nada, não saía leite, porque ela ficava gritando (...) para mim eu estava amamentando, mas não estava (...) Não tinha leite, o meu leite não estava sustentando, eu ficava com o coração partido: vou ter que dar mamadeira pra ela tão pequenininha" (Júlia).

A força da fragilidade da criança de ser "pequenininha" se impõe, manifestando nessas mulheres seus sentimentos maternos, ao mesmo tempo que percebem que sua capacidade para ser nutriz, a princípio "inata”, foge de seu controle.

Tal como a gestação e o parto, também a produção láctea é de significativo valor social na confirmação da mulher como mãe. A disfunção percebida tem um certo caráter punitivo, na medida em que é produtora de manifestações dolorosas.

"Eu imaginava que não tinha leite por isso que doía..." (Janete).

Não só a quantidade de leite eliminada foi significativamente valorizada pelas mulheres, mas também suas características. A aparência da secreção láctea suscitou estranheza nas mulheres estudadas: "colostro, um negócio esquisito, parece água, não é como o leite que sustenta” (Aline).

As mulheres de nosso estudo não consideram o colostro um alimento que dê sustento ao filho, entretanto apesar de ser um "negócio esquisito” não deixam de oferecê-lo ao bebê.

Estudo etnográfico realizado por Bitar (1995), sobre as crenças, costumes e tabus ligados à prática do aleitamento materno pelas mulheres residentes na zona rural de Itapuá, no Estado do Pará, revela aspectos culturais associados à recusa dessas mulheres em oferecer o colostro para o filho. As características do colostro, “amarelo", "aguado" e "pouco", trazem conotação de ser um alimento inadequado à criança. Para elas, o colostro não tem valor nutritivo, não satisfaz, além de produzir algumas situações mórbidas como vômito e dor à criança. Nessa comunidade é comum o costume de contratar com antecedência uma "mãe leiteira" para alimentar a criança nos primeiros dias pósparto.
Praticando amamentação:

medo do bebê se afogar com o leite

Uma das preocupações das mulheres do estudo, para com o filho frágil e dependente de seus cuidados, era o medo de que algo pudesse acontecer a ele, causando inseguranças diante de certos cuidados como: de fazer a criança arrotar, de prestar cuidados de higiene e de curar o umbigo.

O medo apresenta-se como inerente ao ser mãe, conforme podemos observar na fala de Silvia: "sempre ouvi falar que quando a gente é mãe, a gente fica com medo e eu vi que isso é verdade...".

Na definição normativa do caráter moral da mãe, originariamente posta nos manuais de puericultura, perpassa a idéia de fragilidade do corpo infantil, o que incentiva o sentido de proteção e vigília constantes das mães para com os filhos. A este respeito, Del Priore (1993) cita que, no período colonial, inscrevia-se no horizonte mental das mães uma série de conselhos para controlar o corpo de seus filhos, para que este não fosse atingido por malefícios. Fundadas na mesma idéia de fragilidade do corpo infantil, as mulheres de nosso estudo mostram preocupação de que algo pudesse acontecer ao filho, fazendo-as adotar uma vigilância constante, ficando alertas a quaisquer sinais sugestivos de problemas de saúde. Dentre as situações que mostram ser mais geradoras de preocupação na amamentação, está o fato da criança afogar-se com o leite e não arrotar após a mamada.

“Meu medo de dar o leite pra ela é porque é muito e ela engasga, se afoga (...) ela não dá conta do leite.(...) o problema é bastante leite(...) eu vejo que ela está sufocando ... na hora já tiro o peito(...) bato nas costinhas dela(...)é um pouco difícil, porque é mais fácil eu tirare pôr na mamadeira, tanto para mim quanto para ela" (Patrícia).

O medo e a preocupação que evidenciam estão fundados na observação da prática cotidiana, mas também advêm de experiências anteriores vivenciadas na família. Mantendo a mesma lógica que estrutura os significados da amamentação e do corpo materno, as mulheres assumem a responsabilidade e a culpa por não cuidar de forma apropriada do filho.

Praticando amamentação: peito empedrado, bico rachado... O bebê não consegue mamar

Considerando que o significado da amamentação é suprir as necessidades da criança, a manutenção da mesma deve ser garantida, mes- 
mo em situações em que o "peito empedra" e o "bico racha".

“(...) Empedrou no começo (...) ficou enorme (...) estava muito dolorido... o nenê não conseguia mamar...ficou terrível! Fiquei com o peito dando medo, inclusive começou a querer a dar rachadura (...) fez aqueles machucadinhos, mas só aqui na pontinha (...) sumiu normal, porque ele está pegando normal" (Taís).

A pouca importância dada pelas mulheres às manifestações de incômodo, em seu corpo físico, pode ser apreendida na fala de Taís quando se refere ao bico rachado, utilizando termos no diminutivo "machucadinhos". A maior preocupação é o fato do bebê não conseguir mamar. Há de se considerar que tal significado tenha relação com o momento especial, pelo qual as mulheres passavam, um mês após o nascimento do filho, fase em que a amamentação é de reconhecida importância no estabelecimento do vínculo amoroso entre mãe e filho. Nesse sentido, o objeto de seu desejo é corresponder às necessidades do filho, priorizando o seu bem-estar, em detrimento do próprio.

O reconhecimento dos benefícios do leite materno para a criança parece sustentar as decisões dessas mulheres ante essas situações de incômodo e desconforto. A esse respeito, Silva (1997) refere que as mulheres tomam decisões sobre a amamentação, assumindo os riscos e benefícios, e nessa situação os benefícios do ato de amamentar são superiores aos malefícios que porventura aconteçam à sua saúde.

A articulação do que seja amamentação idealizada e as condições reais para sua prática ameaçam a inércia da subjetividade maternal instituída para as mulheres. De modo tênue, as mulheres estudadas expressam o significado de amamentar, tendo por sentido "o corpo para si”, apresentado nas unidades temáticas que se seguem.

Praticando amamentação:

ter para poder dar

No universo pesquisado, o efeito de legitimidade de ser a amamentação uma prática fácil, prazerosa, em que toda mulher é capacitada anatômica e fisiologicamente para exercê-la, não tem peso suficiente para se manter ante a experiência prática e particular de cada mulher. Para poder amamentar é preciso considerar as condições próprias de "ter leite".

"É uma coisa muito boa porque eu sei que eu tenho para poder amamentar" (Lucila).

"Ter para poder amamentar" transcende as capacidades anatômicas e fisiológicas do corpo materno, como evidenciado nas falas a se- guir, quando as mulheres valorizam a necessidade de "ter experiência”, "prática" e "saber", na medida que se manifestam em seus corpos as dissonâncias, ante a suposta condição de amamentação natural instintiva.

"Foi difícil (...) eu não tinha experiência nenhuma como dar de mamar" (Samira).

"Acho que já é do instinto da mulher saber como fazer, quer dizer, saber entre aspas" (Marilda).

Apreendemos que cada mulher vivencia a amamentação de maneira própria, singular e única. Sobre as singularidades, Boltanski (1989) refere que as mesmas têm um caráter efetivamente individual, mas se constróem segundo regras fixas e fazem apelo a um grupo de categorias e de esquemas classificatórios que possuem um caráter coletivo.

Pensar nas especificidades que a amamentação tem para cada mulher, significa desconstruir a visão essencialista e universal que se construiu de nutriz, de um corpo materno supostamente provido de capacidades funcionais para exercer tal função e atender às necessidades da criança, discurso originalmente higienista do século XIX, que, segundo Almeida (1999), não tem sustentação biológica na própria base do fenômeno, assumindo conotação eminentemente ideológica. Alude ainda o mesmo autor, que o fato vivenciado pelas mulheres de querer e poder amamentar interliga as práticas socialmente instituídas à biologia molecular dos peptídios supressores da lactação, evidenciando a impropriedade do reducionismo biológico imputado pelo paradigma de amamentação em vigor. Implicitamente, opera-se um apelo das mulheres para que sejam vistas não como meras produtoras de leite, mas como sujeito, na sua integralidade.

Praticando amamentação: os meus peitos não estão agüentando

Numa cultura comprometida com o ideal materno, espera-se uma adaptação da mãe às necessidades do filho. Entretanto, quando os limites de tolerância à dor se esgotam, as mulheres tendem a buscar alternativas que as aliviem, mesmo que temporariamente, da função.

“Eu dou um jeito de dar, porque tem que dá o peito (...) acho que nem só o peito vai sustentar ele... comprei até o 'Nan' pra dar (...) depois que começou a rachar que foi piorando (...) doía até chorava junto com ele (...) a gente fica desesperada que ele quer mamar (...) meus peitos não estavam agüentando (...) quando eu ia dar de mamar eu ficava nervosa, não pelo nenê, por causa da dor, mas eu dava" (Isabel). 
As mulheres percebem a situação em que se encontram, não somente restritiva às implicações para a criança, mas também para si. Coerentemente com a visão idealizada de mãe que tudo suporta, seus limites estão definidos para o peito: “meus peitos não estão agüentado", isso parece reduzir a carga de culpa de estar eximindo-se do dever de amamentar.

Expressar e deixar valer os imperativos de seus corpos não se constitui uma realidade que se mostra extensiva a todas as mulheres, mas a uma minoria do grupo. Acreditamos que tal fato não ocorra por estarem ausentes nas outras, mas em verdade tais imperativos se mantêm abafados em conformidade com o ideal de maternidade instituído; tudo elas suportam em prol do bem-estar do filho.

Praticando amamentação: pensando naquelas coisas que eu deixo para fazer

Estar em função da criança durante a amamentação pode ser uma situação que a maioria das mulheres de nosso estudo prioriza e se acostuma, no entanto, para Josiana esta dependência vem trazendo desajustes à sua vida: "eu fico dando de mamar para ele e fico pensando naquelas coisas que eu deixo para fazer (...) quando ele acorda, quer mamar (...) quase não deixa eu sair... eu tirar e começa a puxar... eu quero fazer minhas coisas (...)".

Percebemos que o foco no trabalho doméstico reveste-se de um valor especial, ou seja, dá sentido à sua vida de permanentes lidas domésticas. Sobre o trabalho doméstico, Sarti (1996), refere-se aos valores morais fundamentais dos pobres, relacionados ao espaço da casa. O substrato fundamental da construção da identidade feminina é enredado em intermináveis lides domésticas, neste mundo social fortemente recortado pela diferenciação de gênero.

A amamentação é considerada como mais uma atividade dentre as muitas que a mulher tem a desempenhar, sobrecarregando-a e gerando conflitos pessoais e no meio relacional.

"Antes eu fazia minhas coisas bem sossegada, agora tenho ele, nossa! Eu fico doidinha...eu vou fazer uma coisa e deixo pela metade, eu não gosto não (...) ele fica falando pra mim deixar o que eu estou fazendo pra ir dar mamar para ele (...) ele fica falando que eu não estou ligando pra ele ...fica até com raiva, parece que ele é grosso" (Josiana).

Nesse sentido, chama a nossa atenção a falta de suporte que possivelmente estaria dificultando a adaptação da mulher. Com a autonomia restrita à vida doméstica, reconhece a falta de recursos e de apoio, percebendo a ne- cessidade de buscar soluções que são pensadas nos limites da demanda pessoal. Dessa forma, deixa de considerar a possibilidade de socialização das tarefas domésticas e maternas entre os gêneros.

\section{Considerações finais}

No grupo de mulheres estudadas, depreendemos marcas da construção histórico-social de maternidade, como dever, responsabilidade e resignação. A amamentação, engendrada nesse universo moral, reafirma, na prática, a emblemática condição de "ser uma boa mãe".

Sob essa lógica, ordenam-se os significados da conexão estabelecida entre o corpo materno e corpo do filho, por meio da amamentação. As mulheres reafirmam o desejo idealizado de amamentar, para "dar o melhor para o filho", respaldando-se no discurso oficial cientificamente instituído. Entre os limites e possibilidades para a consecução da amamentação idealizada, as mulheres manifestam a conformação de seus corpos, como corpo-função e, tendo por base as experiências vividas em seus próprios corpos, evidenciam a ilegitimidade da amamentação natural e instintiva. Para elas, é preciso "ter (leite, experiência, conhecimento) para poder amamentar".

No universo moral em que as mulheres se abastecem, o recém-nascido é o fator nuclear das atenções, constituindo-se na base de mediação do significado da amamentação (fonte de nutrição, proteção e afeto) e do corpo materno (provedor da fonte de alimento, proteção e afeto). Numa visão reducionista de relação linear de causa e efeito, as mulheres dimensionam o que consideram preocupação e problema na vivência da amamentação. Nos limites do corpo materno e do filho, sustentam suas interpretações atendo-se às manifestações percebidas em seus próprios corpos e, prioritariamente, naquelas percebidas nos corpos de seus filhos. Na conexão entre corpo materno e corpo do filho, os conflitos emergem na medida em que o corpo materno se configura como responsável e culpado pelo "mal jeito", colocando o corpo do filho em condição de prejuízos e perigos.

Os limites entre ser o "corpo para o filho" e de ser o "corpo para si" são ideologicamente conformados por construções culturais de maternidade. No momento em que se encontram as mulheres de nosso estudo, trinta dias pósparto, a relação mãe/filho é estabelecida sob uma apaixonada absorção da mãe para com o filho, emparelhando-se a isso exigências ina- 
diáveis nos cuidados ao bebê/amamentação. No jogo dessa relação, as situações conflitivas podem se apresentar evidenciando formas de negociação da individualidade da mulher e de sua capacidade como doadora de cuidados. Mantendo a conexão com o ideal de maternidade, as mulheres, subliminarmente, reivindicam o sentido de limites do seu corpo: "ter (leite, experiência, conhecimento) para poder amamentar"; "meus peitos não estão agüentando"; "pensando naquelas coisas que eu deixo de fazer".

\section{Referências}

ADESSE, L., 1994. Amamentação: Este Ato Contraditório. Dissertação de Mestrado, Rio de Janeiro: Instituto Fernandes Figueira, Fundação Oswaldo Cruz.

ALMEIDA, J. A. G., 1999. Amamentação: Um Híbrido Natureza-Cultura. Rio de Janeiro: Editora Fiocruz.

ARANTES, C. I. S., 1991. O Fenômeno da Amamentação: Uma Proposta Compreensiva. Dissertação de Mestrado, Ribeirão Preto: Escola de Enfermagem de Ribeirão Preto, Universidade de São Paulo.

ARAÚJO, L. D. S., 1991. Querer/Poder Amamentar: Uma Questão de Representação? Dissertação de Mestrado, Florianópolis: Universidade Federal de Santa Catarina.

ARIÈS, P., 1981. História Social da Criança e da Família. Rio de Janeiro: Editora Guanabara.

BARDIN, L., 1977. Análise de Conteúdo. Lisboa: Edições 70 .

BADINTER, E., 1985. Um Amor Conquistado: O Mito do Amor Materno. Rio de Janeiro: Editora Nova Fronteira.

BITAR, M. A. F., 1995. Aleitamento Materno: Um Estudo Etnográfico sobre os Costumes, Crenças e Tabus Ligados a esta Prática. Dissertação de Mestrado, Belém: Universidade Federal do Pará.

BOLTANSKI, L., 1989. As Classes Sociais e o Corpo. Rio de Janeiro: Editora Graal.

CITELI, M. T., 1998. Reveses da anticoncepção entre mulheres pobres. In: Doença, Sofrimento, Perturbação: Perspectivas Etnográficas (L. F. Duarte \& O F. Leal, org.), pp. 57-77, Rio de Janeiro: Editora Fiocruz.

COSTA, J. F., 1983. Ordem Médica e Norma Familiar. Rio de Janeiro: Editora Graal.

DEL PRIORE, M., 1993. Filhos: Espelho do corpo materno. In: Ao Sul do Corpo (M. Del Priore, org.), pp. 321-330, Rio de Janeiro: Editora José Olympio.

DONZELOT, J., 1980. A Polícia das Famílias. Rio de Janeiro: Editora Graal.

MAUÉS, M. A. M., 1998. "Lugar de Mulher”: Representações sobre os sexos e práticas médicas na Amazônia (Itapuá/Pará). In: Saúde e Doença : Um Olhar

\section{Agradecimentos}

Este trabalho foi elaborado como parte das atividades do VI Programa Interinstitucional de Metodologia de Pesquisa em Gênero, Sexualidade e Saúde Reprodutiva, e teve o apoio financeiro do Núcleo de Estudos de População da Universidade Estadual de Campinas.

Antropológico (P. C. Alves \& M. C. S. Minayo, org.), pp. 113-125, Rio de Janeiro: Editora Fiocruz.

MEAD, M., 1979. Sexo e Temperamento. São Paulo: Perspectiva

NAKANO, A. M. S., 1996. O Aleitamento Materno no Cotidiano Feminino. Tese de Doutorado, Ribeirão Preto: Escola de Enfermagem de Ribeirão Preto, Universidade de São Paulo.

RODRIGUES, J. C., 1986. Tabu do Corpo. Rio de Janeiro: Editora Dois Pontos.

SARTI, C. A., 1996. A Família como Espelho: Um Estudo sobre a Moral dos Pobres. Campinas: Editora Autores Associados.

SILVA, A. A. M., 1990. Amamentação: Fardo ou Desejo? Estudo Histórico-social dos Saberes e Práticas sobre Aleitamento Materno na Sociedade Brasileira. Dissertação de Mestrado, Ribeirão Preto: Faculdade de Medicina de Ribeirão Preto, Universidade de São Paulo.

SILVA, I. A., 1997. Amamentar: Uma Questão de Assumir Riscos ou Garantir Benefícios. São Paulo: Editora Robe.

SOUZA, I. E. O., 1993. O Desvelar do Ser Gestante Diante da Possibilidade de Amamentação. Tese de Doutorado, Rio de Janeiro: Escola de Enfermagem Anna Nery, Universidade Federal do Rio de Janeiro.

VAN DER SAND, I. C. P., 1999. O Bem-Estar da Criança Sempre em Primeiro Lugar: O Processo de Alimentação do Lactente sob a Ótica de Mulheres-mães de Ijuí-RS. Dissertação de Mestrado, São Paulo: Escola de Enfermagem, Universidade de São Paulo.

VICTORA, C. G., 1996. Os Limites do Corpo Sexual: Um Estudo sobre Experiências Corporais de Mulheres Inglesas. Cadernos do NUPACS 2. Porto Alegre: Núcleo de Pesquisa em Antropologia do Corpo e da Saúde, Universidade Federal do Rio Grande do Sul.

Recebido em 19 de março de 2003

Versão final reapresentada em 29 de setembro de 2003 Aprovado em 31 de outubro de 2003 